\title{
Evaluasi Tarif Moda Transportasi Udara Rute Malang - Denpasar Di Bandara Udara Abdul Rachman Saleh Kota Malang Provinsi Jawa Timur Berdasarkan Analisis Biaya Operasional Airline (BOA)
}

\section{Evaluation of Air Transport Mode Rates Malang - Denpasar Route at Abdul Rachman Saleh Airport Malang City East Java Province Based on Airline Operational Cost Analysis}

\author{
Kurnia Hadi Putra ${ }^{1}$, Wisnu Wardana Basuki ${ }^{2}$ \\ ${ }^{1}$ Dosen Jurusan Teknik Sipil, FTSP - ITATS \\ ${ }^{2}$ Mahasiswa Jurusan Teknik Sipil, FTSP - ITATS \\ Jl. Arief Rahman Hakim 100, Surabaya, 60117, adyputra.putra87@ yahoo.com
}

\begin{abstract}
ABSTRAK
Transportasi merupakan usaha untuk memindahkan, menggerakkan, mengangkut atau mengalihkan suatu objek dari suatu tempat ke tempat lain. Transportasi udara merupakan salah satu moda transportasi memiliki karakteristik yang dapat melayani angkutan penumpang dan barang relatif terbatas khususnya barang bernilai tinggi dan membutuhkan waktu cepat, serta dapat melakukan penetrasi keseluruh wilayah yang tidak dapat dijangkau moda transportasi lain. Pentingnya transportasi udara membuat penduduk kota Malang dengan mudah menuju ke pulau dewata yaitu mudah dan cepat. Dengan menggunakan transportasi udara sangatlah efisien dibandingkan rute transportasi darat maupun rute transportasi laut. Dalam transportasi udara dibutuhkan Biaya Operasional Airline untuk menjalankan operasi penerbangan. Biaya Operasional Airline merupakan biaya keseluruhan pengeluaran operasi pada setiap perusahaan maskapai penerbangan meliputi keseluruhan biaya operasi langsung, biaya operasi tidak langsung, dan biaya operasi total. Didalam menganalisis Biaya Operasional Airline dilakukan berdasarkan Revisi KM 26 Tahun 2010. Untuk rute Malang - Denpasar dari bandara udara Abdul Rachman Saleh memiliki jarak tempuh $345 \mathrm{~km}$ per udara, waktu tempuh 1 jam 5 menit dengan pesawat terbang propeller jenis ATR 72. Hasil dari Biaya Operasional Airline yang dianalisis sebesar Rp 53.932.497 dalam sekali penerbangan. Hasil evaluasi tarif berdasarkan Revisi KM 26 Tahun 2010 sebesar Rp 1.057.500 dengan Load Factor 70\% yaitu 51 penumpang, tarif berdasarkan PM 126 Tahun 2015 sebesar Rp 1.159.200, tarif berdasarkan PM 14 Tahun 2016 batas atas sebesar Rp 1.148.000 dan batas bawah sebesar Rp 344.000, tarif yang sedang terjadi saat ini sebesar Rp 648.600. Jadi tarif yang sedang terjadi saat ini adalah sudah ideal.
\end{abstract}

Kata Kunci :Biaya Operasional Airline (BOA), Biaya Operasional, Bandara Udara, Pesawat Terbang, Analisis Tarif.

\section{ABSTRACT}

Transport means efforts to move, drive, carry, or redirect objects from one place to other ones. Air transport is one of transport modes having characteristics of serving limited passengers and freights particularly for high value goods which need fast delivery and can penetrate to all areas that cannot be reached by other transport modes. The importance of air transport eases Malang inhabitants to come to Bali Island fast. Air transport is easier to take than land and sea transports. Air transport requires Airline Operating Cost for operating flight. It refers to the total cost of operating expenses of each airline company covering the total of direct and indirect operating costs. Analysis on Airline Operating Cost was carried out using RevisedMinisterial Decree Number 26 in 2010. Malang-Denpasar route from Abdul Rachman Saleh airport has 
travel distance $345 \mathrm{~km} / \mathrm{air}$, travel time 1 hour 5 minutes by ATR 72 propeller plane. The total Airline Operating Cost was IDR 53,932,497 per flight. The result of tariff evaluation based on the RevisedMinisterial Decree was IDR 1,057,500 with 70\% load factor or around 51 passengers. The tariff based on Ministerial Regulation Number 126 in 2015 was IDR 1,159,200 but the tariff referring to the Ministerial Regulation Number 14 in 2016 was IDR 1,148,000 for upper limit and IDR 344,000 for lower limit, while the existing tariff is IDR 648,600. Thus, the existing tariff has been ideal.

Keywords: Airline Operational Cost, operational cost, airport, plane, tariff analysis.

\section{PENDAHULUAN}

Transportasi merupakan usaha untuk memindahkan, menggerakkan, mengangkut atau mengalihkan suatu objek dari suatu tempat ke tempat lain, di mana di tempat lain objek tersebut lebih bermanfaat atau dapat berguna untuk tujuan-tujuan tertentu. Kota Malang adalah sebuah kota yang terletak di Provinsi Jawa Timur Indonesia. Kota Malang memiliki luas $110.06 \mathrm{~km}^{2}$. Kota dengan jumlah penduduk sampai tahun 2010 sebesar 820.243 jiwa yang terdiri dari 404.553 jiwa penduduk laki-laki, dan penduduk perempuan sebesar 415.690 jiwa. Kepadatan penduduk kurang lebih 7.453 jiwa per $\mathrm{km}^{2}$. Kota Malang ini memiliki bandara udara berjenis domestik yang bernama Bandara Udara Abdul Rachman Saleh yang beralamat yang beralamat di desa Pakis. Bandara udara domestikmerupakan sebuah bandara udara yang mampu menangani penerbangan didalam negara. Bandara domestik tidak memiliki fasilitas bea cukai dan imigrasi serta tidak mampu menangani penerbangan menuju atau dari bandara luar negeri. Untuk lebih tepatnya tentang moda transportasi udara yaitu diambil dari salah satu rute yang lebih banyak dikunjungi oleh penduduk Kota Malang adalah rute menuju ke Kota Denpasar Provinsi Bali. Bali merupakan salah satu provinsi di Indonesia yang wilayahnya terdiri atas satu pulau, yaitu pulau Bali dan beberapa pulau-pulau kecil di sekitarnya. Bali memiliki objek wisata yang sangat beragam, baik wisata alam, wisata budaya, dan wisata bahari. Pentingnya transportasi udara membuat penduduk Kota Malang dengan mudah menuju ke pulau dewata atau pulau bali yaitu mudah dan cepat. Dengan menggunakan transportasi udara sangatlah efisien dibandingkan rute transportasi darat maupun rute transportasi laut. Dalam transportasi udara dibutuhkan Biaya Operasional Airline untuk menjalankan sebuah operasi penerbangan.

\section{TINJAUAN PUSTAKA}

\section{Transportasi Udara}

Transportasi udara merupakan salah satu moda transportasi memiliki karakteristik yang dapat melayani angkutan penumpang dan barang relatif terbatas khususnya barang bernilai tinggi dan membutuhkan waktu cepat, serta dapat melakukan penetrasi sampai keseluruh wilayah yang tidak bisa dijangkau oleh moda transportasi lain.

Dalam menunjang atau menjalankan transportasi udara diperlukan acuan sebuah tarif. Didalam tarif tersebut terdapat sebuah peraturan tarif yang sudah dilansirkan oleh pemerintah Indonesia berdasarkan peraturan dan perhitungan yang ditetapkan, antara lain : 
- Data berdasarkan PM 126 Tahun 2015 :

Tabel 1.Tarif dasar penumpang

\begin{tabular}{|c|c|c|c|}
\hline \multirow[b]{2}{*}{$\begin{array}{l}\text { Kelompok } \\
\text { Jarak (KM) }\end{array}$} & \multicolumn{3}{|c|}{ Tipe Pesawat } \\
\hline & JET & $\begin{array}{l}\text { PROPELLER > } \\
30 \text { TEMPAT } \\
\text { DUDUK }\end{array}$ & $\begin{array}{l}\text { PROPELLER < } \\
30 \text { TEMPAT } \\
\text { DUDUK }\end{array}$ \\
\hline$<150$ & - & 3886 & 7510 \\
\hline $150-225$ & 2931 & 3760 & 7228 \\
\hline $226-300$ & 2888 & 3417 & 6618 \\
\hline $301-375$ & 2515 & 3360 & 6481 \\
\hline $376-450$ & 2421 & 3230 & 6366 \\
\hline $451-600$ & 2300 & 2970 & 6227 \\
\hline $601-750$ & 2167 & 2900 & \\
\hline $751-900$ & 1877 & & \\
\hline $901-1050$ & 1719 & & \\
\hline $1051-1400$ & 1659 & & \\
\hline$>1400$ & 1440 & & \\
\hline
\end{tabular}

Sumber : PM 126 Tahun 2015

- Data berdasarkan PM 14 Tahun 2016 :

Tarif Jarak Penumpang Pelayanan Kelas Ekonomi Angkutan Udara Niaga Berjadwal Dalam Negeri (Pesawat Propeller > 30 Tempat Duduk), antara lain:

Batas Atas $\quad=R p$ 1.148.000,- $($ Batas maksimal tarif $)$

Batas Bawah = Rp 344.000,- $($ Batas minimal tarif $)$

\section{Bandara Udara}

Bandara udara adalah lapangan terbang yang digunakan untuk mendarat dan lepas landas pesawat udara, naik turun penumpang dan / atau kargo dan / atau pos, serta dilengkapi dengan fasilitas keselamatan penerbangan dan sebagai tempat perpindahan antar moda transportasi. Didalam bandara udara memiliki 2 (dua) fasilitas, antara lain :

- Fasilitas Pokok Bandara Udara (Fasilitas sisi udara, fasilitas sisi darat, fasilitas navigasi penerbangan, fasilitas alat bantu penerbangan, fasilitas komunikasi penerbangan, fasilitas elektronika bandara udara).

- Fasilitas Penunjang Bandara Udara (fasilitas penginapan/hotel, fasilitas penyediaan toko dan restoran, fasilitas pergudangan, fasilitas pengelolahan limbah, fasilitas lainnya yang menunjang secara langsung dan tidak langsung kegiatan bandara udara). 


\section{Biaya Operasional Airline (BOA)}

Biaya operasional airline merupakan sejumlah biaya yang harus dikeluarkan oleh suatu perusahaan maskapai penerbangan untuk mendukung operasi atau kegiatan yang dilakukan oleh perusahaan tersebut. Biaya Operasional Airline merupakan biaya keseluruhan pengeluaran operasi pada setiap perusahaan maskapai penerbangan yang meliputi :

- Biaya operasi langsung (Direct Operating Cost) merupakan seluruh biaya yang berhubungan langsung dengan dan tergantung kepada jenis pesawat udara yang dioperasikan dan akan berubah untuk jenis pesawat yang berbeda.

- Biaya operasi tidak langsung (Indirect Operating Cost) merupakan seluruh biaya yang tetap tidak terpengaruh dengan perubahan jenis pesawat udara karena tidak tergantung secara langsung dengan operasi pesawat udara tersebut.

- Biaya operasi total merupakan jumlah dari biaya operasi langsung dan biaya operasi tidak langsung.

\section{METODOLOGI}

Data Jasa Bandara Udara berdasarkan Bandara Udara Abdul Rachman Saleh sebagai berikut :

Tabel 2. Biaya Jasa Bandara Udara Abdul Rachman Saleh

\begin{tabular}{|c|c|c|c|}
\hline No & $\begin{array}{l}\text { Jenis-Jenis Jasa Bandara } \\
\text { Udara }\end{array}$ & Biaya & Keterangan \\
\hline 1 & Airport Tax & Rp 20.000/orang & Biaya untuk Dewasa, Anak, Bayi \\
\hline 2 & Counter Check-In & $\mathrm{Rp} \quad 1.100 /$ orang & $\begin{array}{l}\text { Biaya untuk Dewasa, Anak (Bayi tidak } \\
\text { dipungut biaya) }\end{array}$ \\
\hline 3 & Sewa Ruangan Ber AC & Rp 17.000/bulan & Biaya setiap $\mathrm{m}^{2}$ \\
\hline 4 & Listrik & Rp 421.000/bulan & Biaya setiap Maskapai Penerbangan \\
\hline
\end{tabular}

Sumber : Bandara Udara Abdul Rachman Saleh

Dengan penumpang rata-rata 62 orang dalam sekali penerbangan, didapat biaya yaitu :

Tabel 3. Biaya Perhari Jasa Bandara Udara

\begin{tabular}{|c|c|c|}
\hline No & Jenis-Jenis Jasa Bandara Udara & Biaya \\
\hline 1 & Airport Tax & $\mathrm{Rp} \quad 1.240 .000 /$ hari \\
\hline 2 & Counter Check-in & $68.200 /$ hari \\
\hline \multirow[t]{3}{*}{3} & Sewa Ruangan Ber AC & \\
\hline & - Ruang Flop Ukuran 7,04 m² & 3.989/hari \\
\hline & - Ruang Customer Service Ukuran $18,4 \mathrm{~m}^{2}$ & $10.427 /$ hari \\
\hline 4 & Listrik & 14.033/hari \\
\hline
\end{tabular}

118 | Evaluasi Tarif Moda ... 
Untuk lebih jelas tentang rancangan penelitian, maka dibuatlah dalam sebuah diagram alir sebagai berikut :

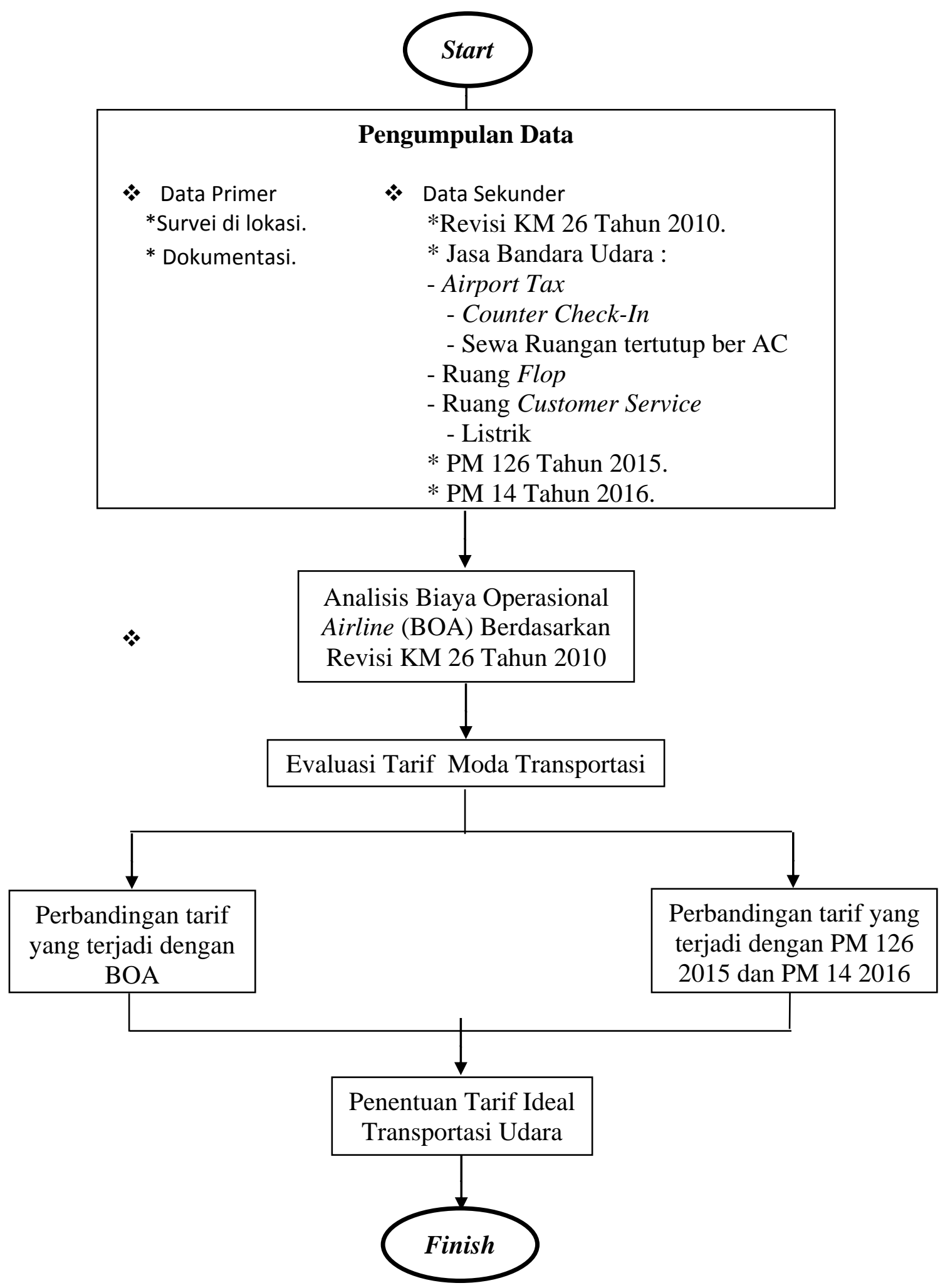


Gambar 1. Diagram Alir Penelitian

\section{ANALISIS DATA \& PEMBAHASAN}

\section{Analisis Biaya Operasional Airline (BOA)}

Analisis Biaya Operasional Airline (BOA) berguna dalam kegiatan membedakan, memilih, meneliti sejumlah biaya yang harus dikeluarkan oleh suatu perusahaan maskapai penerbangan untuk mendukung operasi dalam penerbangan. Dalam menghitung analisis Biaya Operasional Airline (BOA) menggunakan analisis teoritis yang artinya perhitungan dilakukan berdasarkan rumus empiris yang digunakan dengan Revisi KM 26 Tahun 2010 karena menyangkut berbagai macam biaya menjadi 1 (satu) komponen biaya yaitu meliputi biaya operasi langsung tetap, biaya operasi langsung variabel, dan biaya operasi tidak langsung.

Adapun perhitungan lebih jelasnya mengenai Biaya Operasional Airline (BOA) dengan pesawat terbang ATR 72 dapat dilihat pada tabel 4.1, sebagai berikut :

Tabel 4.Analisis Biaya Operasional Airline

\begin{tabular}{|c|c|c|c|c|}
\hline & NO & KOMPONEN BIAYA OPERASI PESAWAT & $\%$ & $\begin{array}{c}R A N G E \\
F L I G H T 1\end{array}$ \\
\hline & \begin{tabular}{c|}
$\mathbf{I}$ \\
1 \\
2 \\
3 \\
4 \\
5
\end{tabular} \mid & $\begin{array}{l}\text { Biaya Operasi Langsung Tetap } \\
\text { Sewa Pesawat } \\
\text { Premi Asuransi Pesawat } \\
\text { Gaji Tetap Awak Pesawat } \\
\text { Gaji Tetap Teknisi } \\
\text { Biaya Training }\end{array}$ & $\begin{array}{c}18,7 \\
7,57 \\
4,1 \\
2,67 \\
0,56\end{array}$ & \begin{tabular}{lr}
\multicolumn{2}{c}{$\mathrm{Rp} / \mathrm{Jam}$} \\
$\mathrm{Rp}$ & 9.100 .000 \\
$\mathrm{Rp}$ & 3.683 .333 \\
$\mathrm{Rp}$ & 1.993 .333 \\
$\mathrm{Rp}$ & 1.300 .000 \\
$\mathrm{Rp}$ & 270.833
\end{tabular} \\
\hline & & $\begin{array}{l}\text { Sub Total } \\
\end{array}$ & 33,6 & Rp 16.347 .499 \\
\hline & \begin{tabular}{r|r} 
II \\
1 \\
2 \\
3 \\
4 \\
5 \\
\end{tabular} & $\begin{array}{l}\text { Biaya Operasi Langsung Variable } \\
\text { Pemakaian BBM ("Avtur ") } \\
\text { Pemakaian Pelumas } \\
\text { Tunjangan Awak Pesawat } \\
\text { Overhaul dan Pemeliharaan Pesawat } \\
\text { Jasa Bandara Udara (Abdul Rachman Saleh) } \\
\text { Airport tax (Wings Air) Rp 20.000/orang } \\
\text { Counter Cek-In Rp 1.100/orang } \\
\text { Sewa Ruangan Tertutup ber AC Rp 17.000/m² } \\
\text { - Ruang Flop Ukuran 7,04 m² } \\
\text { - Ruang Customer Service Ukuran 18,4 } \mathrm{m}^{2} \\
\text { Listrik } \\
\text { Ground Handling } \\
\text { Catering }\end{array}$ & $\begin{array}{l}21,5 \\
0,56 \\
2,49 \\
13,6 \\
0,63\end{array}$ & $\begin{array}{rr}\text { Rp } & 10.481 .419 \\
\text { Rp } & 272.800 \\
\text { Rp } & 1.213 .139 \\
\text { Rp } & 6.632 .708 \\
& \\
\text { Rp } & 1.240 .000 \\
\text { Rp } & 68.200 \\
& \\
\text { Rp } & 3.989 \\
\text { Rp } & 10.427 \\
\text { Rp } & 14.033 \\
\text { Rp } & 1.784 .444 \\
\text { Rp } & 1.141 .233\end{array}$ \\
\hline & & $\begin{array}{c}\text { Sub Total } \\
\text { TOTAL BIAYA OPERASI LANGSUNG }\end{array}$ & \begin{tabular}{|l|}
44,87 \\
78,5 \\
\end{tabular} & $\begin{array}{ll}\mathrm{Rp} & 22.862 .392 \\
\mathrm{Rp} & 39.209 .891 \\
\end{array}$ \\
\hline & \begin{tabular}{r|} 
III \\
1 \\
2
\end{tabular} & $\begin{array}{l}\text { Biaya Operasi Tidak Langsung } \\
\text { Umum dan Organisasi } \\
\text { Pemasaran dan Penjualan (incl : Komisi Agen) }\end{array}$ & $\begin{array}{l}4,24 \\
8,19\end{array}$ & $\begin{array}{ll}\mathrm{Rp} & 2.062 .500 \\
\mathrm{Rp} & 3.985 .648\end{array}$ \\
\hline & & TOTAL BIAYA OPERASI TIDAK LANGSUNG & 12,4 & 6.048 .148 \\
\hline & & $\begin{array}{l}\text { Total Biaya Operasi Sebehm Profit } \\
\text { Profit Margin } 10 \%\end{array}$ & $\begin{array}{l}90,9 \\
9,09\end{array}$ & $\begin{array}{lr}\text { Rp } & 45.258 .039 \\
\text { Rp } & 4.525 .804\end{array}$ \\
\hline Evaluas & & TOTAL BIAYA OPERASI PESAWAT & 100 & $\mathrm{Rp} \quad 49.783 .843$ \\
\hline
\end{tabular}


Didapatkan hasil perhitungan analisis Biaya Operasional Airline (BOA) pada tabel diatas berdasarkan Revisi KM 26 Tahun 2010 dalam sekali penerbangan dengan waktu tempuh selama 1 jam yaitu sebesar Rp 49.783.843. Adapun waktu tempuh dalam penerbangan rute Malang menuju Denpasar membutuhkan waktu tempuh selama 1 jam 5 menit. Jadi untuk melakukan sekali penerbangan dengan rute Malang menuju Denpasar didapatkan biaya operasional airline sebesar Rp 53.932.497,-.

\section{Analisis Tarif Moda Transportasi Udara}

Data yang dipakai untuk melakukan perhitungan analisis tarif Biaya Operasional Airline adalah sebanyak 51 penumpang dengan nilai $70 \%$ load factoryang sudah ditetapkan dari PM 14 Tahun 2016. Jarak tempuh penerbangan rute Malang menuju Denpasar sejauh 345 $\mathrm{km} / \mathrm{udara}$. Kategori pesawat terbang yang digunakan adalah ATR 72 dan memasuki tipe Pesawat Propeller dengan memiliki kapasitas 72 tempat duduk.Maka hasil evaluasi tarif lebih jelasnya dapat dilihat pada tabel 4.2, sebagai berikut :

Tabel 5 Hasil evaluasi tarif moda transportasi udara

\begin{tabular}{|l|l|l|l|}
\hline No & Jenis Tarif & Harga & Keterangan \\
\hline 1 & $\begin{array}{l}\text { Biaya Operasional Airline } \\
\text { berdasarkan Revisi KM 26 } \\
\text { Tahun 2010 }\end{array}$ & Rp 1.057.500 & \\
\hline 2 & PM 126 Tahun 2015 & $\operatorname{Rp~} 1.159 .200$ & \\
\hline \multirow{2}{*}{3} & PM 14 Tahun 2016 & $\operatorname{Rp~} 1.148 .000$ & (Batas Atas) \\
\cline { 3 - 4 } & $\operatorname{Rp~} 344.000$ & (Batas Bawah) \\
\hline \multirow{2}{*}{4} & Sedang terjadi saat ini & $\operatorname{Rp} 593.900$ & (Hari Kerja : Kamis, 30 Maret 2017) \\
\cline { 3 - 4 } & & $\operatorname{Rp} 648.600$ & (Hari Libur : Minggu, 02 April 2017) \\
\hline
\end{tabular}

Sumber : Hasil Penelitian

\section{KESIMPULAN}

Berdasarkan hasil penelitian yang dilakukan terhadap analisis Biaya Operasional Airline (BOA) dan evaluasi tarif transportasi udara dalam sekali penerbangan dengan rute Malang - Denpasar di Bandara Abdul Rachman Saleh Kota Malang Provinsi Jawa Timur, maka dapat dibuat kesimpulan bahwa hasil analisis data mengenai Biaya Operasional Airline (BOA) berdasarkan Revisi KM 26 Tahun 2010 didapatkan biaya sebesar Rp 53.932.497,-dengan jarak tempuh sejauh $345 \mathrm{~km} /$ udara dan waktu tempuh selama 1 jam 5 menit dalam sekali penerbangan rute Malang - Denpasar di Bandara Udara Abdul Rachman Saleh Kota Malang Provinsi Jawa Timur.Hasil penelitian mengenai evaluasi tarif moda transportasi udara dapat disimpulkan bahwa tarif saat ini yang terjadi sudah ideal untuk sekali penerbangan rute Malang menuju Denpasar di Bandara Udara Abdul Rachman Saleh Kota Malang Provinsi Jawa Timur. 


\section{Daftar Pustaka}

Departemen Perhubungan Republik Indonesia (2010). Keputusan Menteri Perhubungan RI Revisi KM 26 Tahun 2010, Analisa dan Evaluasi Mekanisme Formulasi Perhitungan dan Penetapan Tarif Penumpang Pelayanan Kelas Ekonomi Angkutan Udara Niaga Berjadwal Dalam Negeri, Jakarta : Departemen Perhubungan Republik Indonesia.

Departemen Perhubungan Republik Indonesia (2015). Keputusan Menteri Perhubungan RI PM 126 Tahun 2015, Mekanisme Formulasi Perhitungan dan Penetapan Tarif Batas Atas dan Bawah Penumpang Pelayanan Kelas Ekonomi Angkutan Udara Niaga Berjadwal Dalam Negeri, Jakarta : Departemen Perhubungan Republik Indonesia.

Departemen Perhubungan Republik Indonesia (2016). Peraturan Menteri Perhubungan RI PM 14 Tahun 2016, Mekanisme Formulasi Perhitungan dan Penetapan Tarif Batas Atas dan Bawah Penumpang Pelayanan Kelas Ekonomi Angkutan Udara Niaga Berjadwal Dalam Negeri, Jakarta : Departemen Perhubungan Republik Indonesia.

Ilmu Terbang (2008). Fasilitas Alat Bantu Pendaratan, http://www.ilmuterbang.com/artikel-mainmenu-29/teori-penerbangan-mainmenu68/157-fasilitas-bantu-pendaratanPemerintah Kota Malang. 2017. PENDUDUK DAN SOSIOLOGI,

http://malangkota.go.id/sekilas-malang/sejarah-malang/ 